\title{
STUDI ANALISIS KEBUTUHAN PENGEMBANGAN BUKU PANDUAN KESELAMATAN DALAM PEMBELAJARAN PENJASORKES DI SMA DAN SMK KABUPATEN BULELENG
}

\author{
Made Agus Dharmadi ${ }^{1}$, I Made Satyawan ${ }^{2}$, Ni Luh Putu Tuti Ariani ${ }^{3}$ \\ ${ }^{1,3}$ Jurusan Pendidikan Kepelatihan Olahraga, ${ }^{2}$ Jurusan Pendidikan Jasmani Kesehatan dan \\ Rekreasi Fakultas Olahraga dan Kesehatan, Universitas Pendidikan Ganesha \\ Singaraja, Indonesia
}

e-mail: made agus2011@yahoo.com, arianituti@yahoo.com, satyawan made@yahoo.com

\begin{abstract}
Abstrak
Tujuan penelitian ini adalah untuk memperoleh gambaran penggunaan aspek keselamatan dalam pembelajaran penjasorkes, merumuskan dimensi-dimensi panduan keselamatan dan merumuskan draft panduan keselamatan pembelajaran. Penelitian ini adalah merupakan tahap awal penelitian pengembangan berdasarkan analisis kebutuhan melalui studi pustaka, daftar isian dan kuesioner menggali persepsi dan pemahaman guru. Sampel penelitian adalah guru penjasorkes SMA yang ada di kabupaten Buleleng yang berjumlah 15 (12 SMA dan 3 SMK), pengolahan datanya menggunakan deskriptif kualitatif. Berdasarkan hasil dan pembahasan dapat disimpulkan bahwa: 1) Gambaran aspek keselamatan dalam pembelajaran penjasorkes telah tercermin tercermin pada perencanaan pembelajaran, teknik bantuan, pengelolaan kelas dan peralatan olahraga, 2) Dimensi- dimensi yang dibutuhkan dalam pembuatan buku panduan keselamatan pembelajaran penjasorkes; lingkungan tempat berolahraga, fasilitas dan peralatan pembelajaran, perencanaan pembelajaran, pengelolaan kelas, teknik bantuan, 3) Draft formar isi panduan keselamatan dalam pembelajaran penjasorkes dipandang sebagai hal baru yang harus dipenuhi oleh seluruh sekolah sehingga menjadi acuan/petunjuk praktis dalam melaksanakan pembelajaran penjasorkes yang aman.
\end{abstract}

Kata Kunci:, Keselamatan, Penjasorkes, Buku Panduan

\begin{abstract}
The aim of this reserch was to obtain a sketch of the use of the safety aspects of learning penjasorkes, dimensions formulate safety guidelines and formulate draft safety guide learning. This study is an initial stage of development of research based on needs analysis through the study of literature, lists and questionnaires is explore perceptions and understanding teacher. The research sample was penjasorkes high school teacher in the district of Buleleng, amount to 15 (12 high schools and three vocational), processing of data using descriptive qualitative. Based on the results and discussion, it can be concluded that: 1) description of the safety aspects have been reflected in the learning penjasorkes reflected in lesson planning, technical assistance, classroom management and sports equipment, 2) dimensions required in the manufacture of safety guidebooks penjasorkes learning; environment in which to exercise, facilities and equipment of learning, lesson planning, classroom management, technical assistance, 3) Draft guidebook penjasorkes safety in learning is seen as a new thing that must be met by all schools so that the reference learning practical guidance in implementing a safe penjasorkes.
\end{abstract}

Keywords: Guidebook, Penjasorkes, Safety

Jurnal Pendidikan Indonesia | 173 


\section{PENDAHULUAN}

Berdasarkan Undang - Undang Sistem Keolahragaan Nasional Nomor 3 Tahun 2005 Pasal 5 Ayat 3 menyatakan bahwa salah satu prinsip penyelenggaraan keolahrgaan adalah keselamatan dan keamanan, hal ini sungguh masuk di akal karena keselamatan merupakan hal pokok dalam suatu aktivitas apapun bentuknya (UU SKN,2005:5).

$\mathrm{Di}$ lain pihak, organisasi pendidikan jasmani yang ada di United State yakni National Assosiation of Physical Education juga telah melakukan elaborasi, sehingga terbentuk sebuah standar keselamatan dalam olahraga, untuk dijadikan komitmen bersama di dalam pembelajaran olahraga agar selalu mengutamakan keselamatan (Supomo,2000:25). Hal yang sama juga dilakukan oleh Pemerintah Inggris, khususnya yang menangani masalah keolahragaan, juga telah menelorkan prosedur keselamatan dalam olahraga yang di beri judul Safety in Sports, yang di dalamnya memuat tentang kepedulian terhadap keselamatan serta manajemen resiko dan berbagai solusinya sehingga meminimalisir faktor kecelakaan khususnya bidang olahraga (Fuller,2000:20).

Dalam kurikulum pendidikan jasmani, olahraga dan kesehatan (penjasorkes) di Indonesia, unsur keselamatan juga menjadi bagian dari komitmen pembuat kurikulum (Badan Standar Nasional Pendidikan), dengan membuat klausul dalam kurikulum tersebut yakni untuk menciptakan dan selalu memperhatikan keselamatan dalam setiap pembelajarnnya. Hal senada juga disampaikan oleh Melograno (1996:46) bahwa pembelajaran penjasorkes memiliki resiko yang kompleks oleh karenanya maka faktor keselamatan sangatlah penting.

Di satu sisi pendidikan jasmani adalah proses pendidikan yang menggunakan aktivitas jasmani/fisik yang direncanakan secara sistematik bertujuan untuk mengembangkan dan meningkatkan individu secara organik, neuromuskuler, perseptual, kognitif, dan emosional (Rink, 2009:17).

Sesuai dengan pengertian tersebut karakter pembelajaran pendidikan jasmani terletak pada aktifitas fisik, yang tercermin dalam kompetensi dasarnya yaitu kemampuan terhadap suatu teknik/gerak suatu permainan, atletik, senam, uji diri dan sebagainya, dimana kesemuanya itu memiliki faktor resiko dan rentan terjadinya kecelakaan yang dapat berupa cedera keseleo, luka dan bahkan patah dan yang lainnya (Lutan.R,2004:57). Contoh misalnya pada pembelajaran atletik (lempar lembing) dengan peralatan lembing yang cukup berbahaya, maka jika tidak ada panduan keselamatan dalam pelajaran tersebut maka niscaya suatu kecelakaan (seperti luka) akan terjadi, begitu pula pada pelajaran senam yang menggunakan pergerakan otot, sendi yang kompleks, maka jika tidak dilengkapi dengan panduan keselamatan maka niscaya pula cedera (seperti keseleo) akan mudah terjadi.

Berdasarkan hasil penelitian tentang pentingnya unsur keselamatan dalam pembelajaran penjasorkes tercermin dalam temuan yaitu banyaknya cedera yang dialami oleh para siswa SD Negeri di Kabupaten Bantul pada waktu mengikuti proses pembelajaran penjasorkes seperti cedera ringan, yaitu berupa: cedera lecet pada bagian tungkai dan perdarahan pada bagian kaki (Rahajeng, 2006:10).

Sementara di Buleleng, berdasarkan hasil diskusi kecil dengan beberapa guru pendidikan jasmani diberbagai pertemuan seperti seminar, workshop keolahragaan diperoleh informasi bahwa secara ekplisit cedera ringan pada siswa sering terjadi khusunya pada pelajaran senam dan atletik seperti keseleo dan terkilir dan yang lainnya dan secara lebih jauh para guru juga menyatakan bahwa secara khusus Panduan keselamatan dalam pembelajaran penjasorkes belum ada, sehingga acuan untuk melaksanakan dimensi-dimensi keselamatan dalam pembelajaran penjasorkes sama sekali tidak ada. Hal ini 
juga dikuatkan dengan hasil penelitian Dharmadi (2009:93) tentang kebutuhan akan panduan keselamatan dalam pembelajaran penjasorkes sangat dibutuhkan oleh guru-guru penjasorkes pada sekolah menengah yang ada di Bali.

Mencermati kondisi tersebut, Sukarmin (2004:34), menyatakan bahwa cara terbaik untuk menghadapi cedera olahraga adalah dengan mencegahnya. Hal ini sangat tepat, karena mencegah adalah suatu usaha/cara yang paling menentukan dalam menciptakan keadaan aman dan lancar dalam suatu aktivitas, termasuk olahraga. Salah satu unsur mencegah dalam pembelajaran penjasorkes adalah dibuatnya panduan keselamatan dalam setiap pembelajaran penjasorkes sehingga tercipta suasana aman bagi guru, siswa dan lingkungan sekitarnya.

Terkait dengan keselamatan dalam olahraga, negara-negara lain telah memiliki Safety at Sports Regulation, Safety Procedure in Sports dan Safety in Sports Guideline (Ramli,2009:31), sebagai acuan atau panduan dalam mengimplementasikan kegiatan dan pembelajaran olahraga sehingga guru dan siswa memiliki pengetahuan dan pemahaman terhadap konsep keselamatan bagi dirinya dan juga orang lain, sedangkan di Indonesia sepengetahuan penulis, sama sekali belum ada.

Berdasarkan latar belakang tersebut di atas, maka penelitian yang berjudul Studi Analisis Kebutuhan Pengembangan Buku Panduan Keselamatan Dalam Pembelajaran Pendidikan Jasmani, Olahraga dan Kesehatan (Penjasorkes) di SMA Kabupaten Buleleng, ini menjadi urgent untuk segera dilakukan, sebagai kajian awal dalam pengembangan buku panduan keselamatan dalam pembelajaran penjasorkes, pada konteks sistem persekolahan guna menciptakan rasa aman dan nyaman bagi siswa dan masyarakat sekolah dalam setiap pembelajarannya.

Rumusan masalah dalam penelitian ini adalah 1) Bagaimanakah gambaran penggunaan aspek keselamatan dalam pembelajaran penjasorkes di SMA?. 2) Bagaimanakah dimensi-dimensi Panduan keselamatan dalam pembelajaran penjasorkes di SMA? 3) Bagaimanakah draf format isi panduan keselamatan pembelajaran penjasorkes di SMA?

Adapun tujuan penelitian ini adalah untuk memperoleh data awal dan draf produk buku panduan keselamatan pembelajaran penjasorkes pada sekolah dasar di kabupaten Buleleng. Namun secara khusus tujuan penelitian ini adalah: 1) Merumuskan gambaran penggunaan aspek keselamatan dalam pembelajaran penjasorkes di SMA. 2) Merumuskan dimensi-dimensi panduan keselamatan dalam pembelajaran penjasorkes di SMA, 3) Merumuskan pengembangan draf format isi panduan keselamatan pembelajaran penjasorkes di SMA.

Penelitian ini memiliki signifikansi teoretis dan praktis, terutama dalam rangka menggali dan mengembangkan dimensidimensi dan draft format isi panduan yang terkait dengan keselamatan dalam pembelajaran penjasorkes di sekolah dasar, yang secara rinci dijelaskan di bawah ini: 1) Secara teoritis penelitian ini diharapakan dapat bermanfaat untuk pengembangan sistem keolahragaan nasional, khususnya dalam bidang olahraga pendidikan, 2) Secara praktis penelitian ini diharapkan dapat bermanfaat sebagai bahan pertimbangan bagi siswa, guru, pimpinan sekolah, dinas pendidikan dan pemerintah khususnya Kementerian Pendidikan Nasional dan Kebudayaan terkait dengan peningkatan rasa aman dalam pembelajaran dengan membuat/memberlakukan panduan keselamatan pembelajaran penjasorkes di SMA.

\section{METODE}

Penelitian ini merupakan penelitian tahap awal pengembangan, sehingga rancangan penelitian ini adalah rancangan pengembangan yang pada penelitian ini karena keterbatasan dana maka untuk itu 
penelitian ini hanya terbatas pada analisis kebutuhan (need assessment)dalam rangka untuk mengetahui analisis awal pengembangan draft buku panduan keselamatan pembelajaran penjasorkes. Penelitian ini mengambil lokasi pada sekolah menengah atas (SMA/SMK) yang ada di kabupaten Buleleng, yang masingmasing lokasinya tersebar di kota, pinggiran kota dan desa. Masing-masing lokasi tersebut memiliki hetrogenitas, lingkungan, adat kebiasaan yang berbeda, sehingga lokasi tersebut juga dipertimbangkan dalam menentukan sampel penelitian sebagai tempat uji coba nanti. Populasi penelitian ini adalah seluruh guru penjasorkes SMA dan SMK yang ada di kabupaten Buleleng yang berjumlah 30 orang (12 SMA dan 3 SMK, dan sampel penelitian ini diambil secara random sederhana dimana masing-masing sekolah diambil 1 orang guru penjasorkes sehingga jumlah sampel penelitian adalah 15 orang guru penjasorkes. Dari 15 orang guru (sampel) yang diberikan kuesioner, hanya 13 orang guru yang mengembalikan ( 2 guru tidak mengembalikan) sehingga data 13 orang guru inilah yang kemudian di analisis. Teknik pengumpulan data merupakan sarana/alat ukur yang digunakan/diperlukan dalam melaksanakan suatu penelitian, sehingga dalam penelitian ini teknik pengumpulan data yang digunakan adalah studi dokumentasi, daftar isian, dan angket (kuesioner). Data penelitian ini berupa data kualitatif. Oleh karena itu pengolahan datanya menggunakan metode deskriptif kualitatif yaitu digunakan pada data yang membutuhkan pemaknaan secara naratif baik pada isi maupun proses.

\section{HASIL DAN PEMBAHASAN}

Hasil penelitian yang diperoleh
menunjukkan, bahwa gambaran penggunaan aspek keselamatan terlihat dari penyusunan rencana pembelajaran yang dibuat oleh guru penjasorkes SMA/SMK dengan memasukkan unsur-unsur pembelajaran yang aman sehingga tercipta keselamatan bagi siswanya dalam belajar penjasorkes. Hal ini sesuai dengan tujuan perencanaan pembelajaran yakni sebagai petunjuk dan mengarahkan pembelajaran agar sesuai dengan tujuan pembelajaran yang diinginkan serta memperlancar pelaksanaan pembelajaran. Dari data yang diperoleh melalui kuesioner hampir sebagian besar guru penjasorkes 98\% menyatakan bahwa perencanaan pembelajaran yang dibuat berupa silabus, RPP dan sebagainya telah mencantumkan aspek keselamatan dalam pembelajarannya, hal ini menandakan bahwa kesadaran guru terhadap pelaksanaan pembelajaran penjasorkes agar berjalan efektif dan aman sangat besar, hal ini sebenarnya dapat dijadikan modal yang besar dalam menciptakan pembelajaran yang sehat dan aman sehingga menambah semangat dan motivasi siswa dalam belajar.

$\mathrm{Di}$ sisi lain penggunaan aspek keselamatan juga tercermin dalam pemberian bantuan dan pengawasan yang baik dalam setiap pembelajaran penjasorkes. Berdasarkan data yang diperoleh pemberian bantuan dalam pembelajaran hampir menjadi bagian dari cara mengajar untuk menciptakan keselamatan siswa dal belajar. Hampir $100 \%$ guru penjasorkes menerapkan teknik bantuan bagi siswa terutama dalam pembelajaran penjasorkes mata pelajaran senam lantai.

Selanjutnya pengelolaan kelas juga menjadi aspek yang berperan dalam keselamatan siswa, terbukti dari hasil yang ditemukan dalam pembelajaran yang dilakukan oleh guru, hampir $100 \%$ guru menyatakan bahwa pengelolaan kelas yang baik akan dapat menciptakan pembelajaran yang aman. Lebih jauh pengelolaan kelas menurut guru dapat dilakukan melalui; 1) melalui pembelajaran yang berkelompok (kooperatif), 2) pemberian intruksi secara aman, 3) melakukan pantauan dan pengawasan yang baik, 4) mengatur giliran berlatih/mempraktekan secara aman, 5) 
mengingatkan siswa agar selalu berhati-hati dalam melakukan sesuatu hal.

Gambaran aspek keselamatan lainnya tecermin dalam keberadaan peralatan pembelajaran penjasorkes di sekolah, ditemukan bahwa sebesar 53,8\% keberadaan peralatan pembelajaran penjasorkes dalam kondisi lengkap dan sebesar $46,2 \%$ tidak lengkap. Selain itu ditemukan sebesar $61,5 \%$ peralatan yang digunakan untuk pembelajaran penjasorkes layak pakai, dan 38,5\% tidak layak pakai.

Berdasarkan input dari para guru penjasorkes tekait dengan dimensi-dimensi keselamatan dalam pembelajaran penjasorkes adalah sebagai berikut: 1) Dimensi lingkungan sekolah dipandang sebagai suatu hal yang umum dalam aspek keselamatan dalam dalam setiap pembelajaran, berdasarakan kuesioner yang disebar tenyata kondisi lingkungan sekolah yang dimiliki terkait pembelajaran penjasorkes adalah sebagai berikut: bahwa dalam menciptakan aspek keselamatan dalam pembelajaran, kondisi lingkungan sekolah menjadi salah satu yang sangat menentukan, hal ini terbukti bahwa hampir semua guru (100\%) menyatakan bahwa lingkungan tempat berolahraga akan sangat menentukan unsur keselamatan dalam penjasorkes, walau berdasarkan kondisi riil yang ada masih ditemukan lingkungan sekolah yang berada dekat jalan raya $(61,5 \%)$, sehingga lingkungan yang berada dekat dengan jalan raya, memiliki konsekuensi logis terhadap unsur keselamatan, sehingga untuk meminimalisasinya perlu adanya Panduan khusus terkait dengan keselamatan dalam pembelajaran penjasorkes. 2) Dimensi Fasilitas dan Peralatan Pembelajaran; bahwa selain lingkungan tempat berolahraga dimensi fasilitas dan peralatan olahraga juga berperan dalam menciptakan unsur keselamatan dalam pembelajaran, hampir $61,5 \%$ sekolah memiliki lapangan olahraga dengan status milik sendiri, dan hanya $30.9 \%$ luas lapangan yang dimiliki di atas 200 meter persegi, di sisi lain kelengakapan olahraga yang dimiliki sekolah hanya $51,8 \%$ yang dalam kategori lengkap, dan hanya sebagian sekolah $61,5 \%$ peralatan olahraganya dalam kondisi layak, hal ini mencerminkan bahwa ketidaklengkapnya fasilitas dan peralatan olahraga secara tidak langsung akan memengaruhi aspek keselamatan dalam pembelajran penjasorkes. 3) Dimensi perencanaan pembelajaran; bahwa dimensi perencanaan pembelajaran seperti pembuatan Silabus, RPP, Lebar penilaian, daftar hadir dan yang lainnya, dalam kaitannya dengan aspek keselamatan dalam pembelajaran penjasorkes, dapat dikatakan sangat berperan (100\%), pembuatan rencana pembelajaran yang baik, dan sesuai dengan kondisi dan situasi yang ada akan sangat membantu keterlaksanaan pembelajaran dengan lancar dan aman. 4) Dimensi pengelolaan pembelajaran: bahwa di dalam pengelolaan pembelajran penjasorkes, sangat ditentukan salah satunya oleh jumlah siswa, yang mana sebagian besar $(61,5 \%)$ sekolah memiliki jumlah siswa lebih dari 35 orang. Di sisi lain, ketidaksinkronan dalam pengelolaan pembelajaran akan dapat menyebabkan kecelakaan dalam pembelajaran, dan $76,9 \%$ kecelakaan pernah terjadi di sekolah akibat kesalahan pengelolaan pembelajaran. 5) Dimensi teknik bantuan pembelajaran: bahwa dalam pembelajaran penjasorkes, teknik bantuan berolahraga menjadi salah satu hal yang harus dilakukan oleh guru, guna menciptakan rasa aman bagi siswanya, (contoh pembelajaran senam lantai), sehingga pengetahuan keterampilan terhadap teknik bantuan bagi guru sangat diperlukan, hasil ini menunjukan bahwa semua guru $(100 \%)$ memiliki pengetahuan dan keterampilan dalam melakukan teknik bantuan selama proses pembelajaran.

Keberadaan buku panduan keselamatan dalam pembelajaran penjasorkes hampir $100 \%$ guru menyatakan sangat dibutuhkan untuk segera dibuat. Panduan keselamatan yang diinginkan oleh guru dapat berupa buku yang sederhana 
namun menarik dan mudah dipahami serta dipraktekkan. Menurut para guru panduan keselamatan pembelajaran penjasorkes minimal memuat tentang bagaimana cara/metode yang dilakukan untuk meminimalisir terjadinya kecelakaan bagi siswa dalam pembalajaran penjasorkes dalam hal: 1) lingkungan sekolah, 2) perencanaan pembelajaran, 3) fasilitas dan peralatan pembelajaran, 4) pengelolaan kelas, 5) teknik bantuan dalam pembelajaran. Dari hasil tersebut, maka draft format isi panduan keselamatan disusun berdasarkan temuan di atas serta kajian kepustakaan yang diperoleh serta hasil studi di lapangan terkait pembelajaran penjasorkes.

Guna menambah wawasan tentang keselamatan, maka akan ditambahkan dimensi tentang hakikat keselamatan secara epistimologi sampai pada aksiologisnya, sehingga draf buku panduan keselamatan dalam pembelajaran penjasorkes yang akan dibuat adalah meliputi: 1) Pendahuluan (latar belakang, Tujuan), 2) Hakikat Keselamatan (difinisi, fungsi dan manfaat), 3) Pengawasan dan Pengaturan Penunjang Pembelajaran Penjasorkes (lingkungan sekolah, perencanaan pembelajaran, fasilitas dan peralatan pembelajaran, pengelolaan kelas, teknik bantuan dalam pembelajaran), 4) Petunjuk Keselamatan Dalam Aktivitas Outdoor, 5) Petunjuk Keselamatan Cabang Olahraga Khusus (basket, voli, sepakbola, bulutangkis, tenis meja, atletik, senam lantai, renang,

Decara umum draf format isi panduan keselamatan pembelajaran penjasorkes dapat di jelaskan sebagai berikut: 1) Pendahuluan: Dalam bagian ini akan dijelaskan bagaimana latar belakang dari tujuan pembuatan buku ini, dengan menampilkan fakta-fakta akan pentingnya keselamatan dalam pembelajaran penjasorkes, dan pentingnya pembuatan buku ini agar dapat meminimalisir terjadinya kecelakaan dalam pembelajaran penjasorkes, disamping itu pula akan dijelaskan bagaimana tujuan yang ingin dicapai dari penulisan buku Panduan keselamatan ini. 2) Hakikat Keselamatan dalam Penjasorkes: Dalam kajian pada bagian ini, akan dijelaskan bagaimana konsep dasar tentang keselamatan yang meliputi difinisi dan fungsi serta manfaat keselamatan dalam pembelajaran, sehingga mengenalkan pada guru dan siswa lebih jauh tentang pentingnnya keselamatan dalam pembelajaran. 3) Pengawasan dan Pengaturan Unsur Penunjang Pembelajaran Penjasorkes: Pada bagian ini akan dijelaskan tentang bagaimana sebuah pengawasan dan pengaturan unsur penunjang pembelajaran penjasorkes yang meliputi; lingkungan sekolah, perencanaan pembelajaran, fasilitas dan peralatan pembelajaran, pengelolaan kelas, teknik bantuan dalam pembelajaran, dimana pada intinya bagaimana dimensi-dimensi tersebut sangat berperan dalam penciptaan aspek keselamatan dalam pembelajaran penjasorkes. Akan di bahas bagaimana agar dimensi-dimensi tersebut di awasi dan diatur agar menciptakan suasana yang aman dalam belajar. 4) Petunjuk Keselamatan Olahraga Khusus: Pada bagian ini, dijelasakan mengenai petunjukpetunjuk/cara aman dalam proses pembelajaran mengenai cabang-cabang olahraga yang diajarkan di SMA, seperti cabang basket, voli, sepakbola, bulutangkis, tenis meja, atletik, senam lantai, renang. Yang di sesuaikan dengan karakteristik cabang olahraga tersebut sehingga di dalam pelaksanaannya dapat berjalan dengan aman.

\section{SIMPULAN DAN SARAN}

Berdasarkan pembahasan di atas, maka dapat disimpulkan sebagai berikut: 1) Gambaran aspek keselamatan dalam pembelajaran penjasorkes telah tercermin melalui karakteristik mata pelajaran penjasorkes yang sangat beresiko terhadap kecelakaan karena sarat akan aktivitas fisik, peralatan kompleks/berat dan yang lainnya, yang tercermin pada perencanaan pembelajaran, teknik bantuan, pengelolaan 
kelas dan peralatan olahraga. 2) Dimensidimensi yang dibutuhkan dalam pembuatan buku Panduan keselamatan pembelajaran penjasorkes di SMA terdiri dari; Lingkungan tempat berolahraga, fasilitas dan peralatan pembelajaran, perencanaan pembelajaran, pengelolaan kelas, teknik bantuan. 3) Draf format isi panduan keselamatan dalam pembelajaran penjasorkes dipandang sebagai suatu hal baru yang harus dipenuhi oleh seluruh sekolah sehingga menjadi acuan/petunjuk praktis dalam penyususnan buku panduan sehingga pelaksanaan pembelajaran penjasorkes menjadi aman/terhidar dari kecelakaan

Berdasarkan simpulan di atas, maka dapat disarankan sebagai berikut: 1) Mengingat pentingnya buku panduan keselamatan dalam pembelajaran penjasorkes, maka untuk menindaklanjuti hasil studi analisis ini sangat diperlukan penelitian lanjutan pada tahun berikut, sehingga produk berupa buku panduan keselamatan dalam pembelajaran penjasorkes dapat terrealisasi. 2) Bagi setiap satuan pendidikan di sekolah baik di sekolah dasar dan menengah diharapkan nantinya memiliki panduan keselamatan dalam pembelajaran penjasorkes, untuk dijadikan petunjuk praktis dalam meminimalisir terjadinya kecelakaan pada siswa. 3) Bagi pemerintah daerah, pimpinan sekolah diharapkan dapat memberikan dukungan baik moril maupun materiil terkait keselamatan dalam pembelajaran penjasorkes dan bidang yang lainnya (bidang yang beresiko) melalui pengadaan/penyusunan buku panduan, peningkatan pemahaman dan keterampilan menciptakan rasa aman dalam belajar siswa.

\section{DAFTAR PUSTAKA}

Dharmadi. 2009. Pengembangan Model dan Perangkat Pembelajaran Bergaya Afektif Berorientasi Aspek Keselamtan Pada Sekolah Menengan Pertama Di Bali. Laporan Penelitian Stranas Undiksha. Singaraja : Undiksha

Fuller. 2000. Safety In Sport.United Kingdom: HSE Books

Lutan,R. 2004. Perencanaan dan Strategi Pembelajaran Penjaskes. Jakarta: Dirjen Dikdasmen Depdikbud

Melograno,V,J. 1996. Designing The Physical Education Curriculum. United States: Human Kinetics

Rahajeng. 2006. Kecelakaan Dalam Pembelajaran Penjasorkes Di Sekolah Dasar. Skripsi. Yogyakarta

Ramli. 2009. System Manajemen Keselamtan dan Kesehatan Kerja OHSAS 18001. Jakarta: Dian Rakyat

Rink, J. 2009. Designing the Physsical Education Curricullum; Promoting Healthy Life Styles. New York: The McGraw Hill Company

Sukarmin. 2005. Pemenuhan Kebutuhan Keselamatan Unit Kegiatan Mahasiswa Bidang Olahraga. Artikel. Yogyakarta: UNY

Supomo. 2000. Hukum Perburuhan Bidang Keselamatan dan Kesehatan Kerja, Jakarta : PT. Pradnya Paramita

Undang-Undang Sistem Keolahragaan Nasional: UU RI No. 3 Tahun 2005. Jakarta: Sinar Grafika. 